\section{Coal as the Basis of the War Effort}

THE eighth report of the Select Committee on National Expenditure for the session 1942-43, dealing with fuel and power, cannot but arouse further misgiving in regard to the fuel situation in Great Britain. The Selec Committee thinks it would be unwise to look forward to any increase in production in 1943. The substantial increase in output on which the Govermment counted in the White Paper on Coal last year is illusory, and the fact that in the event of a European front being formed it may well become necessary to export increased quantities of coal makes economy the more imperative. In recommending therefore that, in addition to all consumers being emphatically and regularly reminded of the need for stringent economy, and continued attempts to bring home to that small section of the miners guilty of avoidable absenteeism how much really depends on them, the Select Committee reiterates that coal is the very foundation of the total war effort. The general conclusions have a bearing of the highest importance upon the war activities of the nation, and are stated in terms which admit of no misunderstanding. The annual loss, due to normal wastage, of some 20,000 or more men, to which the labour force available in the industry is subject, is expected to be offset during the present year by the entry of 'optants' into the industry and by upgrading to the extent of some 4,000 men, leaving a net loss of about 16,000 men. The total number of men engaged in the industry will therefore inevitably be reduced during the next twelve months below the lowest level at which it has stood since August 1941. Moreover, no further relief can be expected from expedients such as the return of miners from the Home Forces, which have recently made good normal annual wastage.

Unless, therefore, the reduced production consequent upon the diminished labour force is counterbalanced by new factors capable of increasing the output of available labour, a dangerous decline in coal production must occur, with repercussions on the price of coal and the output and cost of munitions. The Committee considers that the evidence does not suggest that any such new factors are likely to make themselves felt, and is clearly not satisfied that the introduction of a comparatively novel type of coalgetting machines in Great Britain or concentration are likely to be effective factors in increasing production. Moreover, while recommending that new experiments should be tried to diminish delays in dealing with cases of avoidable absenteeism, it is pointed out that past experience does not encourage optimism as to a solution of this intractable problem. The Select Committee recommends, it is true, that efforts should be made to accelerate production and delivery of machinery urgently required for further mechanization, and that investigations should be continued to achieve further fuel economies by some industrial users. The fuel economy campaign, both domestic and industrial, should be continued without a break and the public advised on the order of priorities of economies in fuel; in particular, the need for greater economies should be impressed on gas and electricity slot-meter users. The aid of managements and miners should be sought in remedying complaints about inferior fuels.

These recommendations are clearly no more than palliatives. The Select Committee is convinced that a serious reduction in output is likely unless measures of a more far-reaching character than any hitherto proposed are found and put into operation without delay. Important as are the Committee's observations on education and guidance of public opinion and on economy by the consumer, the whole trend of the report strengthens the argument for a great expansion of research into the efficient use of coal raised in a recent report of the Parliamentary and Scientific Committee (see p. 709). From that alone is there the prospect of the real fundamental developments to which the Select Committee looks, albeit it must be admitted that such research is more likely to be a long-range affair and unlikely to yield results which will serve the immediate purpose of relieving the present fuel shortage in Great Britain.

\section{Relaxation Methods in Engineering Mathematics}

Prof. R. V. Southwell delivered the Bakerian Lecture of the Royal Society on June 17, taking as his subject, "On Relaxation Methods: a Mathematics for Engineering Sciences". Engineering calls for computations (for example, of stresses) which need not be very exact, but which must not be restricted to particular shapes of boundary. Its needs are not always met by orthodox mathematical analysis, which in many problems offers a precision that cannot be utilized (by reason of the unavoidable uncertainty of physical data) at the cost of limitations that are felt at every turn. On this account solutions are often sought experimentally, use being made of mathematical analogies (for example, of fluid velocities with electric currents in a conducting sheet).

Relaxation methods-a development of the past eight years-aim at providing engineering science with a mathematics more suited to its needs. Computation is made a tentative process, akin to the 'handscraping' technique whereby, in engineering, a part is brought to elose conformity with a gauge or template. Attention is fixed upon the data of the problem (for example, the loads applied to a structure); and the point of view is adopted that in practice all such data have an unavoidable margin of uncertainty, and therefore 'exact' has no more meaning as applied to computations than it has as applied to measurement. At every stage in a computation effected by relaxation methods, values are recorded of the 'residuals' (that is, 'loads not yet accounted for'). When all such values lie within the margin of uncertainty, further computation is not only unnecessary but also meaningless. Problems concerned with systems of finite freedom have been discussed in earlier lectures : Prof. Southwell dealt in the main with problems governed by partial differential equations in two independent variables. Most of the standard equations have been solved, and without restriction to par. ticular shapes of boundary. Current work is concerned with equations which are non-linear and so present special difficulties.

\section{Welfare of Laboratory Animals}

The Universities Federation for Animal Welfare (U F A W), temporary address, 284 Regent's Park Road, Finchley, London, N.3, as a result of recent correspondence with a number of workers engaged in experiments on animals, finds a widespread desire for experience to be pooled so as to enable the maximum of consideration to be shown for laboratory animals. With the view of helping to give effect to this feeling the Federation has supplied to 130 laboratories, on request, a copy of the recent book "Veterinary Anæsthesia", by Prof. J. G. Wright. At 
the suggestion of a number of research workers, the Federation is proposing further to compile information relating to (1) anæsthesia of rats, rabbits, guinea pigs and other animals not covered by Prof. Wright's book; (2) methods of killing laboratory animals; (3) living conditions, housing, diet, etc., and to invite a small number of experienced men to act as a panel for approving or amending the resulting compilation. UF A W would welcome any views or suggestions relating to these proposals, addressed as above.

\section{Institution of Electrical Engineers : Annual Report}

Some of the salient features of the report for the year 1942-43 of the Council of the Institution of Electrical Engineers may be cited as follows. At the twelve months ending March 31,1943 , the total membership numbered 22,315, and of those there were 11,097 corporate members ; 2,106 elections to all classes of membership were made during the period. During the same year 534 meetings were held in London and at the local centres. The Wireless Section held 12 meetings, the Measurements Section 8 , the Transmission Section 8 , the Installations Section 9 ; and there were six informal meetings. There are nine students sections, and extensive programmes have been arranged by the respective committees during the year.

A number of interim reports has been submitted to the Council by the various special committees and panels appointed to study post-war problems, among the subjects dealt with being "Service Arrangements in Houses, Flats and other Buildings", "The Availability of Electricity Supply", "Domestic Electrifcation" and "Telecommunication Engineering". Re. ports on education and training for engineers and the organization of post-war electrical research have since become available. The subject of standardization has received consideration, and papers relating to this aspect of industrial electrical instruments, single-circuit overhead lines up to $33 \mathrm{kV}$., and integrating electricity meters have been presented. A fourth, on the standardization of motor dimensions, has since been published. The report also deals with various phases of the Institution's war effort, with joint activities with other institutions, and with the subject of education.

\section{Institute of Fuel : Students' Medal}

To encourage the preparation of papers by students of fuel technology, the Council of the Institute of Fuel has decided to make an annual award of a medal, together with a prize consisting of books and/or instruments, to the value of $£ 5$. The award will be made annually for a paper submitted by a student member of the Institute or by a student of any university or technical college in the United Kingdom less than twenty-five years of age, dealing with some subject relating to the preparation or utilization of fuel or allied subjects. Papers must be submitted under a nom de plume, the name and address of the author being enclosed in a sealed envelope and sent with, the paper, and must be received by the Secretary of the Institute, 30 Bram. ham Gardens, London, S.W.5, on or before Septem. ber 1 in any year. In judging the papers submitted, consideration will be given to $(a)$ subject-matter; (b) evidence of analytical power and logic ; (c) construction of paper in so far as it gives evidence of an orderly mind and shows continuity of argument with an orderly development of the theme; $(d)$ English.

\section{Samuel Hahnemann (1755-1843)}

Samuel Christian Friedrich Hahnemane, the founder of homœopathy, was born at Meissen in Saxony on April 10, 1755. He studied medicine at Leipzig and Vienna, and after qualifying in 1779 at Erlangen, settled in Leipzig, where he translated Cullen's "Materia Medica" into German. He first set forth his doctrine of similars in Hufeland's Journal in 1796 and elaborated it in his chief work entitled "Organon der rationellen Heilkunde" in 1810. The characteristic theories on which the system was founded were first 'the doctrine of signatures', according to which diseases or symptoms were cured by the drugs which produce similar morbid changes upon the body, and secondly the view that the action of drugs was intensified by the administration of infinitesimally small doses. He died in Paris on July 2, 1843.

\section{The Night Sky in July}

NEw moon occurs on July 2d. 12h. 44m. U.T. and full moon on July $17 \mathrm{~d}$. $12 \mathrm{~h}$. $21 \mathrm{~m}$. The following conjunctions with the moon take place: July 4 d. $08 \mathrm{~h}$., Jupiter $2^{\circ}$ N.; July 6d. 16h., Venus $0.4^{\circ} \mathrm{S}$.; July 24d. 23h., Mars $4^{\circ}$ N. ; July 28d. 07h., Saturn $3^{\circ} \mathrm{N}$. In addition to the above occultations, Venus is in conjunction with Regulus on July 6d. 19h., Venus $0 \cdot 3^{\circ} \mathrm{N}$. The following occultations of stars brighter than magnitude 6 occur: July $6 \mathrm{~d}$. $16 \mathrm{~h}$. 12.6m., $\alpha$ Leo $(D)$; July 6d. 17h. 27.5m., $\alpha$ Leo $(R)$; July 13d. 21h. 05·7m., 49 Lib $(D)$; July 27d. 2h. $29 \cdot 0 \mathrm{~m}$., $264 B$. Tau $(R)$; July 27 d. $4 \mathrm{~h}$. $15 \cdot 0 \mathrm{~m}$., $\propto$ Tau $(D)$; July 27d. 5h. 23.6m., $\alpha$ Tau $(R)$. The times are given for Greenwich, and $D$ and $R$ refer to disappearance and reappearance respectively. Mercury is in superior conjunction on July. 18 and is unfavourably placed for observation. Venus can be observed as an evening star during the month. The planet sets about $2 \mathrm{~h}$. $10 \mathrm{~m}$. after the sun at the beginning of the month and about $45 \mathrm{~m}$. after the sun at the end of the month. Mars moves from the constellation of Pisces to Aries during July. A remarkable effect is produced by its movement in north declination. At the beginning and end of the month it sets at nearly the same time-about $13 \mathrm{~h} .40 \mathrm{~m}$. Jupiter is in superior conjunction with the sun on July 18. Saturn, in the constellation of Taurus, is a morning star, rising at $1 \mathrm{~h}$. $50 \mathrm{~m}$. and setting at $17 \mathrm{~h} .50 \mathrm{~m}$. in the middle of the month. Times are given approximately for the latitude of Greenwich. The earth is at aphelion on July 4, being a little more than $94 \frac{1}{2}$ million miles from the sun on that date.

\section{Announcements}

THE Lord President of the Council has promoted Dr. B. A. Southgate to be acting director of water pollution research in the Department of Scientific and Industrial Research, to fill the vacancy arising from the appointment of Dr. A. Parker to be director of fuel research.

Frve Turkish undergraduates have just arrived in Britain to study British machine, electrical and mining engineering with scholarships given by the British Council. They are Mustafa Necati Ozigik, Turhan Necat Çtinkale, Halil Sancak, Cavit Erginsoy and Fuat Mericelli. With them is Mr. Mehemet Ali Pamir, an inspector from the Turkish Ministry of Economics, who is taking a course of public administration at the London School of Economics. 